\title{
DIAGNOSTICS OF CRISIS CONDITIONS OF THE AVIATION ENTERPRISE
}

\author{
Larysa Turova', Tetiana Gavrilko²
}

\begin{abstract}
The purpose of the article is to study the systems and methods of diagnostics of the crisis conditions of the aviation enterprise, to justify the role of controlling as a management accounting system in the detection and prevention of crisis phenomena, to clarify the mechanism and iterations of diagnostics of the crisis conditions taking into account the use of appropriate management systems. Methodology. The key provisions of economic and financial theory, methodological and methodological principles of crisis diagnosis of enterprises, presented in the works of Ukrainian and foreign scientists, were used as the theoretical basis of the study. The application of a systemic approach allowed to analyze the essence of diagnostics of crisis conditions, its purpose and objectives. The methods of logical generalization used in the research process allowed to formulate the conclusions on the conditions for the effective implementation of diagnostics of crisis conditions based on improving of the functioning of management accounting systems and management systems. Results. The study allowed us to analyze the factors that causing crisis conditions in the aviation industry. The main methods for diagnosing crisis conditions are analyzed placing emphasis on the special place that belongs to management accounting and the use of management systems when diagnosing crisis conditions. The basic provisions of effective organization of management accounting at aviation enterprises to form the information base at development of the strategy for crisis prevention or recovering from crisis conditions are defined. The peculiarities of diagnostic analysis of the financial condition of the enterprise as a system of diagnostic methods are identified; on the basis of a systemic approach, they allow to establish causal changes in the economic system through quantitative and qualitative measurement of the influence of factors on adjustments and development. Features of different types of diagnostic analysis depending on the hierarchy in the management system, goals and directions of analysis, as well as the availability of information about the problem areas of the enterprise, are discussed. Tasks that need to be implemented to achieve the goal of diagnostic analysis are specified. The necessity of diagnostics of possible crisis conditions of the aviation enterprise with simultaneous risk research and its influence on financial stability of the investigated object is justified. The system of indicator values for diagnostics of a financial condition of the aviation enterprise is offered. The sequence of calculations for the implementation of monitoring and controlling process of the financial condition of aviation enterprises is presented. Practical implications. The approach for diagnosing financial condition of the enterprise, which allows to identify the symptoms and threats of the financial crisis and to develop the policy for prevention (anticipation) of weak signals of a crisis situation based on the analysis, is justified. The conditions of effective application of management accounting systems on the basis of monitoring and controlling and modern methods of diagnostics of the financial condition of aviation enterprises are determined. The directions for improvement of analytical activity on the basis of information systems and technologies for the aviation industry are justified. Value/originality. Results given in the article can be used for further research on the problem of diagnosing the crisis conditions of aviation enterprises.
\end{abstract}

Key words: crisis conditions, diagnostics, management accounting, controlling, monitoring, financial analysis, aviation industry.

JEL Classification: G33, L26, L64

\footnotetext{
Corresponding author:

${ }^{1}$ National Aviation University, Ukraine.

E-mail:0660105265@ukr.net

ORCID: https://orcid.org/0000-0003-3479-5019

ResearcherID: https://publons.com/researcher/AAC-3889-2019

${ }^{2}$ National Aviation University, Ukraine.

E-mail: tan3000@ua.fm

ORCID: https:// orcid.org/0000-0002-2010-307X

ResearcherID: https://publons.com/researcher/S-3805-2018/
} 


\section{Introduction}

The crisis conditions and bankruptcy are integral elements of the development of any industry in the market. The crisis resulting from the pandemic has caused record losses of the aviation industry, amounting to 84 billion USD. The International Air Transport Association (IATA) has named 2020 the worst year in the history of aviation. According to experts, next year will not make a full recovery and although the projected growth may be $55 \%$, the performance of aviation companies will be $29 \%$ lower than in 2019.

According to experts, the Ukrainian aviation industry will need at least one and a half to two years to reach the pre-quarantine period. The problematic situation has also developed with the aviation enterprises. The crisis in the pandemic has worsened even more due to untimely government orders, which are the main share in the production program for many companies.

The slowdown in Ukraine's economic development as a whole is caused by other reasons of domestic and external origin, namely: declining demand for Ukrainian exports, the geopolitical situation in Southeastern Ukraine. The recent global financial crisis has affected all spheres of social production; the aviation industry and the service sector (air transportation) are no exception.

The reasons for these problems to occur were mainly objective in nature. At the same time, an important place belongs to subjective reasons: inefficient use of crisis management tools both at the state level and at the enterprises themselves.

There is an obvious need to find and implement measures to increase the effectiveness of the aviation industry and the aviation enterprises, which requires both systematic research and practical action on successful ways to prevent crises and overcome them.

Thus, at present, the formation of diagnostic systems for the aviation enterprises, which will promote their crisis management, makes special sense. The tasks of management accounting in the creation of such diagnostic systems should be to form an information base on controlled indicators and provide them to stakeholders for analysis and further management decision-making.

\section{Tasks and methods of diagnostics of the crisis conditions}

In the work of the aviation industry (AI) in recent years, there has been a deterioration in the financial and economic condition of enterprises, most of which are still operating at a loss. Thus, the current state of the AI of Ukraine cannot be considered anything other than a crisis.

The government should currently contribute to the further development of AI. Ukraine has great prospects for the development of the aircraft industry due to the high demand for domestic aircraft in the world, which AI of Ukraine is trying to meet. However, the enterprises themselves must, first of all, take measures to overcome the crisis, properly assessing their current positions and, taking into account their strengths and weaknesses, form an adequate development strategy.

The process of diagnostics of the crisis conditions of aviation enterprises should be aimed not only at creating an information system that would provide a comprehensive and systematic assessment of all activities of enterprises, including key financial indicators, but also to identify opportunities for improvement.

The purpose of diagnostics of the crisis conditions is timely recognition of signs and nature of trends in the functioning of enterprises, identification of factors that cause negative consequences, the formation of an effective program to prevent further development of crisis phenomena by improving the relevance of enterprise management.

The initial result of diagnostics is the adoption of optimal decisions, taking into account the features and characteristics of the situation that arose, to adjust the operation of all components of the system and ways to implement them on the basis of assessing the degree of impact of harmful actions on the deviation in criterial values.

The task of diagnostics is not only to assess the condition of the object at a particular time, but also to predict its behavior after the application of appropriate measures, as well as in the absence of corrective action to improve the situation.

Depending on the policy of the top management, the peculiarities of the enterprise, the availability of personnel of the appropriate qualification, the following methods of diagnostics of the crisis conditions can be used:

- analytical, based on contactless methods due to statistical information, the use of a comprehensive analysis of financial and economic indicators of the enterprise;

- expert, which gives the opportunity to evaluate the information from experts presented using contact methods; 
- dynamic programming based on solving management problems using mathematical models; - linear programming allowing you to optimize the achievement of a quantified goal.

\section{The role of management accounting in the diagnostics of the crisis conditions}

In the diagnostics of the crisis conditions of the aviation industry, management accounting and the use of appropriate management systems are of particular importance.

Management accounting (MA), or internal accounting, means the collection and analysis of information for the management of the organization at all levels.

It is a misconception of many managers that MA is a subsystem of accounting and is limited to the field of finance, because it allows you to track unacceptable deviations of the actual parameters of the enterprise from planned (regulatory) elements, identify their causes and make informed management decisions.

In order for the MA data to lead to the desired result, the following actions must be performed:

- To identify the main objectives of the structural units of the enterprise, which should be consistent with its mission and overall development strategy.

- To specify the sub-goals and objectives with the definition of indicators for assessing the effectiveness of their achievement.

- To determine the main and secondary indicators of importance for each task.

- To distribute benchmarks based on the functions of responsibility centers.

- To establish target values of control indicators, which will ensure the possibility of implementing the processes of forming plans and monitoring their implementation (Burkovska, 2012).

The obtained results of management accounting can serve as an information basis for further analysis and development of a strategy for crisis prevention or crisis management.

It is very important to assess the possible preconditions and results of changes that could affect the activities of the aviation enterprise in order to identify threats and prevent the development of crisis phenomena.

To implement the tasks of preventive crisis management, it is mandatory to conduct preventive monitoring of the enterprise environment, both internal and external, the formation of the information base on indicators that reflect the level of success of the enterprise determining the vector of possible actions to identify crisis threats.

Thus, one of the most important tasks of crisis management is to diagnose the state of the aircraft industry, the use of effective tools for diagnostic analysis, which will create a basis for assessing the performance of the enterprise and will be the basis for adequate decisions on further development.

\section{Features of diagnostic analysis of financial condition}

Diagnostic analysis is a type of analysis that differs in goals, objectives and includes a system of diagnostic methods that, based on a systematic approach, allows to establish causal changes in the economic system through quantitative and qualitative measurement of factors influencing this change and development. Taking into account the goals and directions of diagnostic analysis, the possibility of obtaining comprehensive information on the areas of activity of the enterprise, which fall into the "problem" area, the decision is made to choose one (or more) of the existing types:

- diagnostic rapid analysis;

- comprehensive diagnostic analysis;

- diagnostic analysis of functional areas;

diagnostic analysis of thematic issues (in particular, diagnostic analysis of financial condition).

The purpose of the diagnostic analysis of the financial condition of the enterprise is to identify existing and potential deviations from stable operation on the basis of typical features that are specific only to this violation, prevention (control) of their occurrence and transformation into "bottlenecks", which can delay the achievement of goals and objectives, jeopardizing both current and strategic activities. Based on the above, diagnostic analysis of financial condition can identify "symptoms" of economic illness.

To achieve this goal, the diagnostic analysis of financial condition should solve the following tasks:

1) systemic comprehensive organically interconnected study of external and internal environmental factors that describe changes in the environment of the enterprise to identify threats and new opportunities (this applies to both global and specific economic environment);

2) timely identification of factors that ensure sustainability or lead to a breach of financial condition in the short and long term; 
3) determination of the target parameters of the enterprise and the criteria for assessing their impact on its financial condition at each stage of the life cycle;

4) determination of the causal links between changes in factors and the system (because a change in any factor can change the whole system) and measuring changes in financial condition (economic system) in quantitative and qualitative terms from the negative impact now and in the future;

5) building of a model for assessing and diagnosing the financial condition for different uses of resources;

6) determination of the degree of risk of a crisis situation at any stage of the life cycle; substantiation of the limit of the enterprise's entry into crisis;

7) development of a system of measures aimed at finding ways to prevent bankruptcy, the development of managerial influences in order to bring the system in the right direction and further strengthen the financial condition.

Since there is a problem in obtaining a unified idea of the object of study as a system as a whole in the process of diagnostic analysis, diagnostic and systemic analysis are closely intertwined. At present, such problems are related to the lack of a single methodological basis for reliable determination of the financial condition of the airline or operating company (air carrier, airport, etc.).

Therefore, the diagnostics of the possible crisis conditions of the aviation enterprise should include a study of risk and its impact on the financial stability of the object under study.

Risk assessment is based on a comprehensive (scientific, technical, technological, marketing, sociological, etc.) research of the object of study, taking into account external influences, construction and analysis of the chain of events under the conditions of various risk factors.

Studies show that to date there is no complete system of risk assessment indicators. In our opinion, the basic methodological principles of forming a system of controlling and diagnostics of the financial condition of the aviation enterprise and the development of a set of initial risk indicators include:

- compliance of the system of indicators with the objectives of the study, which means their ability to identify and assess the degree of influence of a certain group of risk factors on the object of diagnosis (industry or region for the meso level);
- availability and accessibility of information support for empirical research;

- the presence of a sufficient number of research periods to form a certain trend of changes in the values of the indicator (all periods must be the same);

- providing the possibility of forming a statistical base, which would contain information on the level and dynamics of change of indicators, which would be a prerequisite for the development of risk assessment models;

- quantitative measurability;

- the availability of conditions for the construction of adequate algorithms for calculating indicators; - a high degree of variability and relative awareness, a clear and unambiguous definition of the nature of the impact on the level of risk of the object of study; - the optimal number of indicators from each area of research, the exclusion of indicators that duplicate each other.

To implement the process of monitoring and controlling the financial condition of airlines, we offer the following algorithm of calculations: - determining the availability and size of possible financial resources on the basis of calculating the value of the current business of the enterprise; - determining the level of security and efficiency of attracting financial resources based on the calculation of a system of analytical indicators and indicators of financial condition;

- analysing the level of organization of financial management;

- the formation of an integrated indicator as the main indicator of the availability and use of financial potential, which allows to predict the future state of the enterprise, to identify financial reserves and opportunities, to increase the efficiency of management in general.

At the same time, their successful functioning in the modern business environment is impossible without a defined strategy for the development of aviation enterprises (Voronkova, 2017). Ensuring a stable position in a competitive business space and increasing entrepreneurial capital is possible only if the management of aviation enterprises forms an effective development strategy.

\section{Approaches to the diagnostics of the crisis conditions}

The generalization of literature sources and practices of aviation enterprises allows to single out the list of indicators that will diagnose the financial 
condition of the enterprise, identify symptoms and threats of the financial crisis and based on the analysis to develop a policy to prevent (anticipate) weak signals of crisis situation.

In our opinion, the main independent indicators for assessing the financial condition of the enterprise should include:

- Asset mobility (Current / Non-current assets).

- Accounts payable turnover (Net sales income / Current liabilities).

- Return on equity (Net sales income / Equity).

- Return on assets (Balance / Net sales income).

- Provision with own current assets ((Current assets - Current liabilities) / Current assets).

- Concentration of loan capital (Long-term liabilities + Current liabilities) / Balance sheet).

- Debt coverage with equity ((Equity / (Ensuring subsequent expenses and payments + Long-term liabilities + Current liabilities)).

Modern scientific literature sufficiently covers the issue of assessing the financial condition of the enterprise, taking into account the industry characteristics of its operation. From the available variety of financial indicators, the manager, owner or other person who makes financial decisions can choose the most adapted ones to the specifics of a particular enterprise.

A financial ratio can be a criterion for making a management decision, if it has a constant calculation algorithm for the enterprise and it is set by the owner, manager or state regulatory or target value. According to M. Bartoli, these requirements are met by such financial indicators as:

- liquidity ratios (the literature shows the standard values, at the same time it is possible to set own standards, guided by the chosen policy of calculations);

- coefficients of financial stability (the literature shows the standard values, at the same time it is possible to set own standards, guided by the chosen policy of calculations);

- profitability ratios (usually there is an average industry value, the indicative levels of these indicators in competing companies are set by owners or managers);

- turnover ratios (normative or recommended values can be used; when the management sets the lower limit of values, the specifics of the sphere of operation of the enterprise are taken into account); - coefficients underlying the models for determining the probability of bankruptcy (there is a sufficient variety of models of foreign and domestic scientists, adapted to the characteristics of certain economic sectors);

- indicators of investment efficiency (characterized by a unified nature);

- indicators of the conditions and movement of cash flows (relevant standards have commercial banks that use these indicators in assessing the creditworthiness of the borrower);

- integrated ratios, which make it possible to assess the overall financial condition, financial stability, the feasibility of which is determined by the peculiarities of the assessment needs;

- indicators of operational analysis (the criterion is the break-even point in kind or value, calculated at a particular enterprise);

- indicators (standards) of risk (often determined by complex economic and mathematical models to establish standards require expert methods) (Chernysh, 2012).

Given the sufficient effectiveness of factor analysis and diagnosis, assessing the financial condition, it is advisable to use the analysis of the dynamics and structure of the balance sheet, income and expenses, cash flow dynamics and more. Based on the characteristics of these indicators (use to characterize the process), it is problematic to determine their quantitative values (only some structural indicators can be an exception).

For diagnosis it is not enough just to calculate the value of these indicators, you should be able to interpret the situation and assess the parameters of the actual financial condition of the enterprise AI.

Due to the lack of a permanent list of evaluation indicators, according to Professor Blank I.O., theorists and practitioners in the field of diagnosis have an individual, often subjective, approach to solving this problem, so the use of computer tools to improve the reliability of the obtained results is justified (Blank, 2006).

The presence of modern information technologies opens up new opportunities for management accounting (monitoring and controlling financial and economic activities), their use is a kind of driver of economic development.

The use of traditional tools for the implementation of analytical procedures does not allow for timely and quality decision-making both in relation to the enterprise as a whole and for individual activities. The choice of modern information systems and technologies should be based on such factors as the cost of their acquisition and implementation, the level of their profitability, efficiency in terms of 
achieving the desired goals for the company, staff skills, the need for analytical work and its volume (Bartoli, 1994).

Implementation of processes for improving analytical activities based on information systems and technologies for enterprises with large volumes of operations is necessary, according to Theo Postma, for a number of the following reasons:

- large capacity of information arrays used in enterprises and their diversity in terms of unification when used by different departments of the enterprise;

- a variety of sources of information concerning both the external and internal environment;

- lack of ability to process data online with the involvement of interested users (Postma, 1999).

The outlined problems for aviation enterprises should be solved through the introduction of a computer information analytical system, which should be characterized by the presence of stages preceding the direct analysis of data using appropriate modern technologies (Data Warehouse, Data Mart) and analytical tools (OLAP, Data Mining).

The use of standard professional software products "1C: Accounting", "PARUS", "Galaktika", SAP in the case of their adaptation to the peculiarities of the production activities of the enterprise requires additional costs; asset revaluation procedures are also quite time consuming, and although they can be performed on the basis of Microsoft EXCEL, it is obvious that this is insufficient for effective accounting in enterprises (Burkovska, 2012).

Obtaining the results of management accounting allows the analysis of financial capacity, reserves and potential resources of the enterprise in order to form an anti-crisis program; it is important to have preventive measures to implement innovations in the aviation enterprise.

\section{Conclusions}

The study has made it possible to establish that diagnostics in the aviation enterprises is an important means of achieving the goals of the enterprise, acts as a subfunction of the control function and should be based on the agreed use of all procedures of assessment, analysis and identification.

Implementation of management accounting systems, based on monitoring and controlling and modern methods of ddiagnostics of crisis conditions of aviation enterprises, requires:

- training (retraining, advanced training) of employees;

- approbation of accounting procedures on real data of the enterprise for a certain accounting period (on a control example) with the involvement of system developers;

- approval (adjustment) of permanent regulations for the operation of such systems based on the results of their experimental (trial) operation;

- introduction of new automation systems for enterprise management to solve problems of financial diagnostics or adaptation of existing ones.

Improvements in management accounting, as well as other further research on diagnostics of crisis conditions, will help to increase the efficiency of aviation companies and prevent the threat of their bankruptcy.

\section{References:}

Bartoli, M. (1994). Diagnostic d'entreprise. L'economique a l'epreuve du social - P., InterEditions, 324 p. Blank, I. A. (2006). Antikrizisnoye finansovoye upravleniye predpriyatiyem [Anti-crisis financial management of the enterprise]. Kyiv: Elga, Nika-Center. (in Ukrainian)

Burkovska, A. V. (2012). Kompleksnyi pidkhid do otsinky finansovoho stanu pidpryiemstva [A comprehensive approach to assessing the financial condition of the enterprise]. Scientific works of Poltava state. Agrarian Academy, vol. 1(4), pp. 73-77.

Voronkova, T. E. Bankrutstvo pidpryiemstva ta shliakhy yoho podolannia [Bankruptcy of the enterprise and ways to overcome it]. International scientific journal "Internauka", no. 2, pp. 39-43.

Kozlyanchenko, O. M. (2011). Informatsiine zabezpechennia analizu finansovoho stanu pidpryiemstva pry zahrozi bankrutstva [Information support of the analysis of a financial condition of the enterprise at threat of bankruptcy]. Actual problems of economy, no. 10(112), pp. 182-187.

Postma, T. (1999). Organizational diagnosis in practice: a cross-classification analysis using the DEL-technique. Oxford, vol. 17, no. 6, p. 584-597.

Chernish, S. S. (2012). Problemy zastosuvannia metodyk analizu finansovoho stanu na vitchyznianykh pidpryiemstvakh [Problems of application of methods of the analysis of a financial condition at the domestic enterprises]. Innovative economy, no. 5, pp. 142-146. 